\title{
POR QUE O TEMPO SÓ CORRE PARA FRENTE E NUNCA PARA TRÁS? UMA PROPOSTA UTILIZANDO TEXTOS DE DIVULGAÇÃO CIENTÍFICA NO ENSINO DE FÍSICA
}

WHY DOES TIME ONLY RUN FORWARDS AND NEVER BACKWARDS? A PROPOSAL USING SCIENTIFIC DISSEMINATION TEXTS IN PHYSICS TEACHING

\author{
André Luís Miranda de Barcellos Coelho ${ }^{1}$ \\ ${ }^{1}$ Universidade de Brasília.
}

\begin{abstract}
Resumo
Após tomar contato com o problema da possibilidade de reversão temporal nas estruturas lógicomatemáticas das teorias físicas pela dra. Marina Cortês (Universidade de Edimburgo) no Perimeter Institute, retornei ao Brasil decidido a trabalhar este tema com meus estudantes. $O$ foco da proposta deste trabalho é a discussão na escola básica de alguns limites das teorias físicas e, portanto, da física ela mesma como disciplina. Fazemos isso por meio do uso de textos de divulgação científica, inspirados na proposta de leitura em três momentos de Solé. Pretende-se tornar claro que as ciências naturais são também um empreendimento proeminentemente humano, passível de revisão e certamente menos absoluto do que se costuma crer. Em especial, abordar este tema que notavelmente é e foi negligenciado na história das ciências físicas. O que procuramos ao utilizar textos de divulgação científica foi justamente vislumbrar uma possibilidade coerente e realizável de efetivar este desejo.
\end{abstract}

Palavras-chave: Texto de divulgação científica. Ensino de Física. Ensino de Ciências. Física moderna. 


\begin{abstract}
After my contact with the problem of the possibility of temporal reversal in the logical-mathematical structures of physical theories by Dr. Marina Cortês (University of Edinburgh) at the Perimeter Institute, I returned to Brazil determined to work on this topic with my students. The focus of the proposal of this work is the discussion in the high school of some limits of the physical theories and, therefore, of the physics itself. We do this through the use of texts of scientific dissemination, inspired by the reading proposal in three moments of Sole. It is intended to make clear that the natural sciences are also a prominently human endeavor, reviewable and certainly less absolute than is commonly believed. In particular, addressing this subject which is remarkably and has been neglected in the history of the physical sciences. What we were looking for when using scientific texts was to envision a coherent and achievable possibility of fulfilling this desire.
\end{abstract}

Keywords: Text of scientific dissemination. Physics teaching. Science teaching. Modern physics.

\title{
I. CONTEXTO
}

A dra. Marina Cortês do instituto de astronomia da Universidade de Edimburgo ganhou notoriedade recentemente após publicar um artigo em colaboração com Lee Smolin do Perimeter Institute for Theoretical Physics (CORTÊS, 2018), no qual propõe uma teoria de base que impõe irreversibilidade temporal aos modelos físicos. Cortês também é divulgadora científica e frequentemente realiza palestras e conferências sobre o tema de seu trabalho. Tive o prazer de assistir uma de suas palestras de título Why is time always moving forwards and never backwards? (2017) (Por que o tempo sempre está se movendo para frente e nunca para trás, em português) no Perimeter Institute, Canadá. Para uma plateia de professores de ciências de várias nacionalidades, ela encantou-nos com sua brilhante retórica e seu fascinante argumento que propunha a necessidade imperativa de uma reestruturação basal nas teorias físicas. Tudo porque elas preveem, desde Newton e Galileu, a possibilidade matemática de reversibilidade temporal. Este problema é desde então resolvido simplesmente impondo que as condições iniciais determinam também um tempo inicial e por conseguinte a evolução temporal observada. A grande questão é que à medida que os problemas a serem resolvidos ficam cada vez mais complexos e precisamos voltar no tempo para descrever apropriadamente um fenômeno a seta do tempo passa a ser uma escolha arbitrária tipicamente coerente com a empiria. Porém nada nas teorias físicas impõe este sentido em detrimento ao outro. Esta questão é particularmente sensível na área de atuação da dra. Cortês que é a cosmologia.

Retornei ao Brasil decidido a trazer para meus estudantes essa questão interessantíssima que não apenas diz respeito às teorias físicas, mas também à natureza da ciência e seus processos da ciência. A questão, entretanto, era: como? A reversibilidade temporal nas estruturas lógico-matemáticas das teorias físicas não é um assunto relevante per se para estudantes do ensino médio brasileiro que tradicionalmente estudam ciências naturais de 
maneira postular e propedêutica. Entretanto este tem potencial interessante por apresentar algumas características do empreendimento científico que são pouco exploradas no ensino básico tais como a possibilidade de revisão das teorias científicas, os aspectos humanos envolvidos na produção científica e como ela pode ser desenvolvida.

Uma resposta a esta questão me foi sugerida pelo professor Roberto R. da Silva no âmbito da disciplina Divulgação Científica do programa de pós-graduação em Educação em Ciências da Universidade de Brasília a quem agradeço pela dedicação e disponibilidade. Este trabalho é fruto dos debates e leituras realizadas neste espaço.

\section{A DIVULGAÇÃO CIENTÍFICA NO ENSINO DE CIÊNCIAS}

A utilização de textos de divulgação científica em aulas de ciências é tema de muitos estudos. Apesar de, numa primeira análise, parecer algo de simples e desejável utilização, o que muitos desses estudos revelam é que é preciso, no mínimo, cautela. Textos de divulgação científica que não foram produzidos com o propósito de serem utilizados em sala de aula podem trazer mais desafios do que se espera. Comumente estes textos trazem conceitos revistos e reflexões sobre os processos científicos muito menos postulares e desarticulados do que são tradicionalmente trabalhados em salas de aula de ciências naturais. Isto pode conduzir a uma indesejável incerteza sobre o que está sendo, pretensamente, ensinado, por exemplo.

Seja como for, e levando em conta este contexto de controvérsias em relação ao uso de texto de divulgação científica em salas de aula de ciências naturais, é preciso discutir sobre o tema com mais profundidade dado o potencial de tais textos para o ensino de ciências. Dada a polissemia da expressão, para iniciar esse debate, em geral, os autores buscam explicitar o que entendem por divulgação científica, suas principais características e formatos. Só então é possível tecer alguma reflexão mais profícua sobre a questão do uso didático desses textos.

Uma comum conceituação utilizada remete-se a Bueno (1985) que classifica a divulgação científica como um gênero de difusão científica ${ }^{1}$. Para ele as espécies de difusão são classificadas de acordo com o público-alvo a que se destinam. Dessa forma, um texto que se destina a comunicar para o grande público uma recente descoberta científica é diferente daquele que se veicula em uma revista acadêmica destinada a especialistas da área. Apesar da diversidade de comunicações e formatos de divulgação científica muito raramente o potencial educacional é explorado. Esse potencial educacional de materiais sobre ciência publicados em jornais e revistas foi e é explorado por diversos autores. Reis (1967) já fazia apontamentos sobre a importância do papel educativo de artigos e notícias. Silva Almeida (1999), por exemplo, realizaram uma ampla revisão de estudos sobre o funcionamento de textos alternativos ao livro didático (textos literários, artigos originais e textos de divulgação científica) no ensino, sob a perspectiva do papel da leitura nas aulas de ciências. Tratando mais especificamente dos textos de divulgação, encontramos em Almeida (1998) uma discussão sobre as contribuições desse tipo de material ao ensino no sentido de dar destaque a valores associados às condições de produção do conhecimento científico, assim como de aproximar o estudante de diferentes discursos e formas de argumentação, presentes

\footnotetext{
${ }^{1}$ Para Bueno (1985) difusão é todo e qualquer processo ou recurso utilizado para a veiculação de informações científicas e tecnológicas.
} 
nesses materiais. Em outra linha de pesquisa, na interface entre educação formal e informal, Gabana, Lunardi Terrazan (2003) investigaram a utilização dos materiais de divulgação em sala de aula, propondo roteiros para guiar os professores em seu trabalho com esse tipo de material. Alvetti (1999), dentro de uma perspectiva de renovação dos conteúdos programáticos escolares, tece uma investigação sobre as potencialidades pedagógicas dos textos publicados pela Revista Ciência Hoje na formação inicial e continuada de professores de Física.

Neste contexto, o que se espera do ensino de ciências e como os textos de divulgação científica podem apoiar estes objetivos? Esta pergunta motiva muitas contribuições de diversos especialistas. Um ponto de vista muito defendido é que o ensino de [Ciências] deve preparar o estudante para uma intervenção mais crítica na realidade que o cerca, e não apenas lhe apresentar ferramentas para o ingresso na universidade (RIBEIRO, 2005). Se defende o uso de textos de divulgação científica como instrumentos que permitam olhares múltiplos ao empreendimento científico. Não apenas sobre seus resultados e achados, mas também sobre seus processos. Na esteira dessa concepção, alinhamo-nos a ela para propor a utilização de textos sobre a dra. Marina Cortês e da revista Ciência Hoje que tratam sobre o assunto da possibilidade de reversibilidade temporal nas teorias físicas com o intuito central de trazer para a sala de aula de ensino médio esses olhares múltiplos a que se referem os autores citados ${ }^{2}$.

\section{O COMPROMISSO COM O LETRAMENTO CIENTÍFICO E O USO DE TEXTOS DE DIVULGAÇÃO CIENTÍFICA}

A quase totalidade de nossos documentos norteadores da educação básica dá conta de que o ensino de ciências tem um compromisso indispensável com o chamado letramento científico. A BNCC para o ensino fundamental, por exemplo, na página 321 traz:

[...] Portanto, ao longo do Ensino Fundamental, a área de Ciências da Natureza tem um compromisso com o desenvolvimento do letramento científico, que envolve a capacidade de compreender e interpretar o mundo (natural, social e tecnológico), mas também de transformá-lo com base nos aportes teóricos e processuais das ciências. (BRASIL, 2018)

Este compromisso com o letramento científico da população é amplamente presente nos discursos hegemônicos da área de ensino de ciências. Um bom exemplo é o movimento CTS (Ciência Tecnologia e Sociedade) que enfatiza a premente necessidade de compreender a ciência, seus métodos e processos, além de sua natureza e implicações sociais para que um cidadão possa tomar para si a responsabilidade de tomar decisões de maneira mais consciente. Desde as locais (como decidir tomar ou não os antibióticos prescritos pelo médico) até as globais (como a participação de um referendo sobre a construção ou não

\footnotetext{
${ }^{2}$ A saber: o caráter inerentemente provisório das teorias científicas, a possibilidade permanente de revisão dessas teorias e a dimensão humana consubstanciada nos dilemas e histórias pessoais dos cientistas que propõe revisões/adequações/novidades nas teorias científicas.
} 
de uma hidrelétrica), como reitera Sasseron et. al. em seu livro Alfabetização Científica na Prática (SASSERON, 2017).

Apesar de, numa primeira aproximação, todos estejam se referindo ao mesmo objeto quando dizem sobre letramento científico, este termo é bastante polissêmico. Um exemplo dessa polissemia é o entendimento do PISA em comparação ao Currículo Em Movimento (DISTRITO FEDERAL, 2018) que desenvolvemos em um trabalho recente:

Apesar de estarem, na primeira aproximação, em convergência ao concordarem sobre a importância do letramento científico como função do ensino de Ciências, o PISA o entende de maneira quase antagônica do Currículo em Movimento. Observe que o PISA se ocupa em avaliar a educação na ciência (vide seção 2.1), enquanto que o Currículo em Movimento, do conhecimento científico no cotidiano. Essa diferença é mais do que perfunctória meramente, revela concepções sobre o ensino muito conflitantes. (DE BARCELLOS COELHO, 2020 pg 98)

Por conta desses deslocamentos de sentido, alguns autores preferem utilizar outros termos tais como Alfabetização Científica ou Enculturação Científica. Ainda assim, é preciso esclarecer o que se quer dizer com esses termos, pois estes também são termos polissêmicos.

Apesar do entendimento de que os objetivos do ensino de ciências estão associados ao letramento científico ser bastante hegemônico, essa questão da polissemia incomoda alguns autores. Talvez o mais proeminente autor contraegemônico sobre este tema seja Morris Herbert Shamos. Na década de 90, Shamos escreve seu livro The Myth of Scientific Literacy (1996) no qual discute sobre o que considera uma alucinação do letramento científico. Se pergunta se é possível (ou mesmo desejável) alfabetizar cientificamente a população. Entre tantas outras contribuições, o autor avalia a polissemia do termo letramento científico e variantes como um objetivo vago demais. Entre suas análises, numa retrospectiva histórica, demonstra que o maciço investimento motivado pela crise ${ }^{3}$ na educação científica da década de 80 nos EUA não trouxe, na prática, (quase) nenhum retorno. Para o autor fica clara a necessidade urgente de se repensar esse consenso.

Neste contexto de controvérsias, entretanto, há um certo consenso que aponta na direção da necessidade de tornar o ensino de ciências mais significativo para os estudantes. Isto passa, entre outros pontos, pela compreensão da natureza do empreendimento científico e seus processos. Sobre este aspecto, este trabalho adiciona uma modesta contribuição ao esforço de trazer para sala de aula temas científicos que possuem este potencial educacional utilizando para tanto textos de divulgação científica.

\section{SOBRE OS TEXTOS UTILIZADOS E MÉTODO DE APLICAÇÃO}

Infelizmente a dra. Marina Cortês não escreveu nenhum texto de divulgação científica sobre o assunto de seu artigo vencedor do prêmio Buchalter de Cosmologia que trata

\footnotetext{
${ }^{3}$ Shamos dedica um capítulo de seu livro discutindo essa crise e chega a conclusão de que ela foi, na realidade, fabricada e motivada pelos cortes de recursos para a área de educação nos EUA da década de 80.
} 
sobre a reversibilidade do tempo nas teorias físicas. Ela, entretanto, foi extensivamente entrevistada e há algumas palestras dela sobre o assunto em vídeo disponíveis na internet (CORTÊS, 2017) (SILVA, 2015). O tema também foi abordado em algumas revistas de divulgação científica como a Revista Ciência Hoje. Há um texto nesta revista, em especial, que nos parece interessante para atingir os fins anunciados anteriormente. Trata-se do texto intitulado A Mecânica Quântica das Viagens no Tempo presente na edição 290 de Março de 2012 escrito pelo professor Ernesto F. Galvão do Instituto de Física da Universidade Federal Fluminense (GALVÃO, 2012). Outro texto que utilizaremos é uma reportagem feita em 2014 e publicada no jornal português Público de título Queremos descobrir por que é que o tempo está sempre a avançar e nunca recua. Trata-se de uma entrevista com a professora Marina Cortês que enfatiza sua trajetória pessoal, além, evidentemente, de, em linhas gerais, trazer as principais ideias dela sobre o tema. Utilizamos um fragmento dessa entrevista, apenas as 11 primeiras perguntas.

Inspiramo-nos no trabalho de Verenna B. Gomes, Mayara S. de Melo e Roberto R. da Silva (GOMES et al, 2019) para propor uma leitura efetiva desses textos em três momentos ${ }^{4}$. Neste trabalho os autores propõem uma maneira de trabalhar textos de divulgação científica na perspectiva de formação de leitores.

Nossa estratégia foi pensada para ser aplicada em 4 encontros no Ensino Médio. No primeiro encontro, a proposta é a leitura em três momentos da entrevista da dra. Marina Cortês ao jornal Público (GERSCHENFELD, 2014). No segundo encontro, trabalhamos um conceito fundamental da Relatividade Geral no qual um referencial acelerado é equivalente a um espaço-tempo curvo. Fazemos isso utilizando duas atividades do material didático disponibilizado gratuitamente pelo Perimeter Institute intitulado Revoluções da Ciência (PERIMETER, 2013, pg. 9 a 15). No terceiro encontro, trabalhamos uma noção fundamental da Mecânica Quântica que é a ideia de uma ciência probabilística em detrimento a uma determinística. Fazemos isso utilizando, mais uma vez, o referido material didático (PERIMETER, 2013, pg. 22 a 28). No último encontro, voltamo-nos ao texto de divulgação científica. Dessa vez, também em 3 momentos, lemos o texto selecionado para este trabalho da Revista Ciência Hoje.

A proposta pode ser expandida para um número maior de aulas caso se procure explorar outros conceitos relacionados à física moderna. É completamente compatível - e até desejável - abordar noções de relatividade restrita, por exemplo. Ademais, esta proposta se centra em trabalhar aspectos relacionados aos processos da ciência e de sua natureza. Por isto, não nos ocupamos em descrever detalhadamente as atividades relacionadas aos conteúdos selecionados. Sobre isto, entretanto, é importante destacar que o material didático selecionado para as aulas 2 e 3 traz esses elementos. Ao abordar o conceito de espaço curvo na relatividade geral, por exemplo, é proposta uma reflexão sobre modelos científicos para a queda dos corpos. Posto em confronto a leitura newtoniana sobre a queda dos corpos com um modelo alternativo em termos somente de aceleração, os estudantes são convidados a reverem certezas e admitirem que estas não passam de constructos de uma teoria (e,

\footnotetext{
${ }^{4}$ Proposto por Solé, trata-se de um modelo interativo que afirma haver dois processos simultâneos que acontecem quando lemos. Um ascendente (das letras, palavras frases etc) e outro descendente (conhecimentos prévios, recursos cognitivos para antecipações etc). Neste mesmo modelo é proposto três momentos da leitura: antes, durante e depois.
} 
portanto, podem ser revistos). Isto dito, recomenda-se a utilização de uma abordagem com essa característica em possíveis aplicações modificadas.

\section{IV.1. UMA LEITURA EM 3 MOMENTOS}

Voltemo-nos agora a descrever com mais detalhes como estes textos de divulgação científica são utilizados na presente proposta. Como já dito, inspiramo-nos na proposta de uma leitura em 3 momentos concebida por Gomes et al (2019). Nesta proposta a leitura do texto é dividida em 3 momentos denominados antes, durante e depois da leitura. Tendo isto em vista, se propõe as seguintes atividades para cada um desses momentos:

Antes da leitura: Ler apenas os subtítulos e projetar uma expectativa sobre o texto. Isto é feito coletivamente. Um tempo é dado para que os estudantes leiam os subtítulos e imaginem o teor do conteúdo desenvolvido em cada um deles. O professor então convida os estudantes a compartilharem suas expectativas. O objetivo é realizar uma leitura superficial não apenas do texto, mas também da compreensão prévia demonstrada pelos estudantes sobre os temas abordados no texto.

Durante a leitura: Os estudantes são convidados a responderem um questionário sobre as principais ideias abordadas no texto durante sua leitura. Após a leitura de cada subseção eles respondem uma ou duas questões sobre o que acabaram de ler. Este questionário é inteiramente constituído de questões de múltipla escolha. Procura-se com esta atividade verificar a capacidade do estudante de articular o que foi lido no texto com o significado que busca-se alcançar no texto. Os questionários construídos para esta proposta encontram-se disponíveis no anexo 1 e 2.

Depois da leitura: Os estudantes são convidados a compartilharem o que entenderam do texto. Para cada subseção do texto, promove-se um momento no qual eles socializam suas respostas. A presente proposta vislumbra a organização em pequenos grupos e a produção de respostas por grupo ao invés de individuais. Após este momento o professor conduz um debate com a turma inteira, discutindo os principais pontos que julgam relevantes.

\section{CONSIDERAÇÕES FINAIS}

O nosso ensino de ciências é bastante marcado pelo livro didático. Das propostas curriculares ao planejamento das aulas, as mesmas características encontradas nos livros didáticos aparecem. Um ensino marcado por ser propedêutico e segmentário, apoiado por livros que preconizam a memorização e a repetição. Neste cenário, os textos de divulgação científica oferecem uma alternativa para o ensino de ciências. Evidentemente, há desafios e riscos associados à sua utilização e ela requer certo preparo e ambiente. É preciso, por exemplo, ao utilizar esses textos no ensino de ciências relacioná-los a conhecimentos prévios dos alunos. O que pode aumentar as chances de tornar significativo o uso de textos de divulgação científica em sala de aula.

Textos de divulgação científica, em geral, não possuem as mesmas características de textos de livros didáticos. Estes costumam ser bastante focalizados e compactados e raramente trazem discussões sobre os processos de construção do conhecimento. Os textos de divulgação, por sua vez, são mais diversificados, pouco compactados e, em geral, focados 
nos processos. Esta diferença pode inibir a utilização de textos de divulgação científica por professores em suas salas de aula, o que exige um certo realinhamento metodológico. Neste sentido, utilizar textos de divulgação científica em sala de aula também significa criar autonomia em relação aos livros didáticos que, normalmente, pautam o desenvolvimento dos trabalhados na escola básica.

O desafio de implementar o uso de textos de divulgação científica em sala de aula vale a pena? Isto é, é desejável que os professores e estudantes se apartem do tradicional livro didático (ainda que momentaneamente) e se debrucem sobre questões mais gerais e focadas nos processos de construção do conhecimento? Certamente há vantagens nessa incursão. Entretanto, é pertinente lembrar dos requisitos para utilização de tais textos em sala de aula. Utilizá-los exige do professor concepções sobre educação e sobre o ensino que o permitam trazer para sua sala de aula o controverso e o contra hegemônico em relação aos temas que trabalha. Isto significa, sobretudo, espaço para o diálogo e para o contraditório que são características não muito comuns em nossas salas de aula, especialmente de ciências. É sobre este alinhamento que se organiza a proposta apresentada neste trabalho. Há, evidentemente, muitas formas de trazer para nossas salas de aula estes elementos. $\mathrm{O}$ que procuramos ao utilizar textos de divulgação científica aliados a atividades didáticas que abordam aspectos relacionados aos processos da ciência foi justamente vislumbrar uma possibilidade coerente e realizável de efetivar este desejo.

\section{REFERÊNCIAS}

CORTÊS, Marina; SMOLIN, Lee. Reversing the irreversible: from limit cycles to emergent time symmetry. Physical Review D, 2018.

BUENO, Wilson da Costa. Jornalismo científico: conceitos e funções. Ciência e cultura, v. 37, n. 9, p. 1420-1427, 1985.

REIS, J. Divulgação científica. Ciência e Cultura, SBPC, v.19(4), 1967.

SILVA, C. H. ALMEIDA, M. J. P. M. Uma revisão de trabalhos sobre o funcionamento de textos alternativos ao livro didático no ensino de Física. In: Atas do II Encontro de Pesquisa em Educação em Ciências - ENPEC. Valinhos, SP, 1999.

ALMEIDA, J. P. M. de SILVA, H. C. O texto escrito na educação em Física: enfoque na divulgação científica. In: ALMEIDA, J. P. M. de SILVA, H. C. Linguagens, Leituras e Ensino da Ciência. Campinas: Mercado das Letras: Associação de Leitura do Brasil ALB, 1998

GABANA, M.; LUNARDI G. TERRAZAN, E. A. Textos de divulgação científica: analisando uma estratégia didática para o Ensino Médio. In: Atas do IV Encontro Nacional de Pesquisa em Educação em Ciências ENPEC. Bauru, SP, 2003.

ALVETTI, M.A.S. DELIZOICOV, D. Ensino de Física Moderna e Contemporânea e a Revista Ciência Hoje. Dissertação de Mestrado. Florianópolis: UFSC, 1999. 
RIBEIRO, Renata A., and Maria Regina D. KAWAMURA. A ciência em diferentes vozes: uma análise de textos de divulgação científica. ENCONTRO NACIONAL DE PESQUISA EM ENSINO DE CIÊNCIAS 5 (2005).

BRASIL, Base Comum Curricular para o Ensino Fundamental.

SASSERON,Lúcia Helena; MACHADO, Vítor Fabrício. Alfabetização Científica na Prática Inovando a Forma de Ensinar Física. Editora Livraria da Física. 2017

FEDERAL, DISTRITO. Currículo em Movimento da Educação Básica: Ensino FundamentalAnos Finais. 2ł Edição. SEEDF. Brasília. 2018.

DE BARCELLOS COELHO, André Luís Miranda. Identificando fragilidades no Ensino de Ciência na Secretaria de Estado de Educação do Distrito Federal. Revista Com Censo: Estudos Educacionais do Distrito Federal, v. 7, n. 4, p. 93-101, 2020.

SHAMOS, Morris H. The Myth of Scientific Literacy. Liberal Education, v. 82, n. 3, p. 44-49, 1996.

CORTÊS, Marina. Sessão por Marina Cortês, do Instituto de Astrofísica e Ciências do Espaço - Por que não anda o tempo para trás? Internet. 2017. Disponível em: <http:/ /divulgacao.iastro.pt/ $\mathrm{pt}$ /feature/por-que-nao-anda-o-tempo-para-tras/> Acessado em: 08/11/2019

GALVÃO, Ernesto F. A Mecânica Quântica das Viagens no Tempo. Revista Ciência Hoje. v. $49,2012$.

GOMES, V. B.; MELO, M. S. de; SILVA, R. R da. Estratégias de leitura aplicadas ao texto de divulgação científica. 2019.

GERSCHENFELD, Ana. Queremos descobrir por que é que o tempo está sempre a avançar e nunca recua. Dezembro de 2014. Jornal Público. Disponível em: <https://www.publico.pt/2014/12/ 08/ciencia/noticia/queremos-descobrir-por-que-e-que-o-tempo-esta-sempre-a-avancar-e-nunca-recuaAcessado em: 22/11/2019

PERIMETER, Instituto. Revoluções na Ciência. Inspirações Perimeter. Livro 3. Perimeter Institute for Theoretical Physics. 2013. 